\title{
Miscellany
}

\section{Mental health officer (MHO) status: part-time doctors}

The BMA is urging doctors to submit Industrial Tribunal (IT) claims as a result of recent legal decisions casting doubt upon the exclusion of part-time doctors from the benefits of MHO status. MHO status enables each year of service after 20 years as an MHO to be doubled, along with retirement at age 55. Doctors might have a claim for a bigger pension if: first, they have worked part-time in mental health since 1976 and not been credited with MHO status for this service; and second, if this part-time working when combined with any full-time working in mental health totals more than 20 years calendar service or might do so before retirement. If this criteria is satisfied, doctors should immediately contact their local BMA office with a view to submitting an IT claim. Any delay might result in loss of entitlement to claim. For further information contact: Carmel Turner, Public Affairs Division, BMA, BMA House, Tavistock Square, London WC1H 9JP (Telephone: 0171383 6254).

\section{National Lottery Charities Board launches new health and social research grants programme}

These grants are aimed at charities and voluntary organisations wishing to pursue medical and social research projects into health. The research can be undertaken in university departments and research institutes in collaboration with a charity or voluntary organisation. The application line will be open until 9 October 1998. Completed applications must be received, together with a full research proposal by 30 October 1998. The grants will be announced in Spring 1999. For further information contact: Ruth Jones, National Lottery Charities Board Press Office on 0171 747 5200/227.

\section{MIND Inquiry into social exclusion follows evidence of intolerance and discrimination}

This Inquiry entitled Creating Accepting Communities is headed by a Panel who will be inviting religious groups, business leaders, statutory and voluntary organisations and users of mental health services to give written or oral evidence during four day-long hearings in London during the Summer and Autumn of
1998 , or at the regional Inquiry roadshows in each of the six MIND regions in England and Wales. A key objective is to develop a Code of Practice with practical solutions for overcoming social exclusion. The Panel are also requesting examples of successful projects where community integration and inclusion have been achieved. The Inquiry team have already sent over 5000 questionnaires, and are appealing for anyone with experience as an individual, an organisation or a business to ring the MIND Inquiry Line on 01714900811 for more information or write to: The MIND Inquiry, Kemp House, 152-160 City Road, London ECl 2NP.

\section{The IMAGO Multi-Lingual Psychotherapy Centre (MIPC)}

This recently opened centre aims to address the problem that many people can be excluded from psychotherapeutic help mainly due to the fact that psychotherapy in our multi-lingual society is generally provided in English. The MLPC sees as one of its tasks, the creation of clinical space for discussion and further papers on this area of psychotherapeutic practice and experience. They aim to create a forum with ongoing meetings, discussions and supervision groups as well as expanding its network of multi-lingual therapists. For those who are interested in involvement with this organisation or may require further information contact: Ali Zarbafi (Telephone: 01817470408 ) or IMAGO, 24 Maryon Mews, London NW3 2PU (Telephone/Fax: 0171 431 7170).

\section{New publications}

Understanding Attention Deficit Hyperactivity Disorder is a new booklet published by Mind. Aimed at parents, teachers and carers, the new booklet suggests a number of avenues of help for those who are worried about their children's behaviour. The booklet also looks at possible causes and the likely impact of childhood behavioural problems in adult life and contains a list of useful addresses and suggestions. The booklet is available from MIND Publications, 15-19 Broadway, London E15 4BQ, priced \&1 plus A5 SAE (Telephone: 0181519 2122).

Carers National Association has teamed up with The Samaritans to produce two new booklets When caring becomes $a$ crisis and When the 